\title{
Tumores de colisión en tiroides: carcinoma papilar y metástasis de carcinoma renal a células claras
}

\section{Collision tumors in the thyroid: papillary carcinoma and metastases of clear cell renal cell carcinoma}

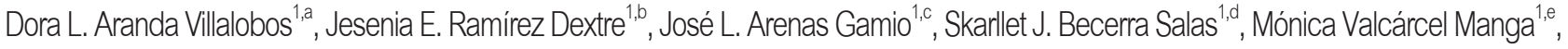 \\ Daniel A. Alva Sandoval ${ }^{1, f}$
}

${ }^{1}$ Hospital Nacional Guillermo Almenara Irigoyen, EsSalud. Lima, Perú.

${ }^{a}$ Cirujana de cabeza cuello y maxilofacial, ORCID: 0000-0002-6193-9797

${ }^{b}$ Médica Oncóloga, ORCID: 0000-0002-1310-893X

'Médico Patólogo, ORCID: 0000-0002-2679-6778

${ }^{d}$ Cirujana de cabeza cuello y maxilofacial, ORCID: 0000-0003-4946-8408

${ }^{e}$ Cirujana de cabeza cuello y maxilofacial, ORCID: 0000-0003-2161-0740

'Cirujano de cabeza cuello y maxilofacial, ORCID: 0000-0002-8273-0159

Correspondencia:

Dora Aranda Villalobos

dora_aranda@yahoo.es

Recibido: 23 de enero 2021

Aprobado: 17 de marzo 2021

Publicación en línea: 15 de abril 2021

Conflictos de interés: Los autores

declaran no tener conflictos de interés.

Fuente de financiamiento:

Autofinanciado

Citar como: Aranda D, Ramírez J, Arenas J, Becerra S, Valcárcel M, Alva $D$. Tumores de colisión en tiroides: carcinoma papilar y metástais de carcinoma renal a células claras. An Fac med. 2020;81(4):432-5. DOI: https://doi. org/10.15381/anales.v81i4.19223
An Fac med. 2020;81(4):432-5. / DOI: https://doi.org/10.15381/anales.v81i4.19223

Resumen

Los tumores de colisión son neoplasias poco comunes, requieren terapias combinadas tratando independientemente cada tumor. La presentación en la glándula tiroides es rara. Reportamos el caso de un paciente de 55 años con diagnóstico de carcinoma renal a células claras; la tomografía corporal reportó nódulos pulmonares y hepáticos sugestivos de metástasis. Oncologia indicó tratamiento con sunitinib. Once meses después, la tomografía de control reportó múltiples nódulos tiroideos. Se realizó tiroidectomía total, con informe anatomopatológico: carcinoma papilar de tiroides y metástasis de carcinoma renal a células claras. Recibió ablación con $80 \mathrm{mCi}$ de iodo 131; luego hormonosupresión con levotiroxina.

Palabras clave: Neoplasias de la Tiroides; Cáncer Papilar Tiroideo; Neoplasias Renales (fuente: DeCS BIREME).

Abstract

Collision tumors are rare neoplasms, they require combination therapy for the treatment of each tumor independently. We describe the case of a 55 year old patient diagnosed with clear cell renal cell carcinoma; whole body computed tomography reported pulmonary and hepatic nodules suggestive of metastatic disease. Oncology indicated sunitib therapy. Eleven months later, evaluation with computed tomography reported multiple thyroid nodules. Total thyroidectomy was performed, with anatomo-pathological report: papillary thyroid carcinoma and metastases of clear cell renal cell carcinoma. He received ablation with $80 \mathrm{mCi}$ of radioactive iodine (I-131); then thyroid hormone suppressive therapy with levothyroxine.

Keywords: Thyroid Neoplasms; Thyroid Cancer, Papillary; Kidney Neoplasms (source: MeSH NLM). 


\section{INTRODUCCIÓN}

Los tumores de colisión se definen como la coexistencia de dos tipos histológicos distintos de tumores malignos en un mismo órgano y que a la vez están separados por tejido normal; estos tumores pueden provenir de líneas celulares del mismo órgano, o combinar células neoplásicas de órganos adyacentes o metástasis ${ }^{(1-4)}$. A nivel de la tiroides, los tumores de colisión son raros, siendo los más frecuentes aquellos que son el resultado de una combinación de cáncer papilar de tiroides con carcinoma medular de tiroides o carcinoma folicular ${ }^{(3-6)}$. Por otro lado, en relación a los tumores de colisión por metástasis, uno de los carcinomas con muy rara metástasis a tiroides, es el renal, el cual a nivel global representa el $3 \%$ del total de tumores en los adultos y presenta metástasis a tiroides entre un $7 \%$ a $15 \%$ de los casos.

Dentro de las líneas celulares de cáncer renal que han sido reportadas en las metástasis a tiroides tenemos la variedad a células claras ${ }^{(7-10)}$, cuya presentación clínica como nódulo tiroideo palpable es rara, siendo más frecuente un agrandamiento difuso no doloroso ${ }^{(8,10)}$. El presente artículo describe el caso de un paciente con tumor de colisión: metástasis de carcinoma renal a células claras (enfermedad metastásica) y carcinoma papilar de tiroides variante papilar y folicular (tumor en un órgano primario).

\section{REPORTE DE CASO}

Paciente varón de 55 años con antecedente de biopsia con guía ecográfica de tumor renal derecho dos años atrás, el informe de anatomía patológica fue de carcinoma a células claras. El estudio tomográfico corporal reportó marcado incremento de tamaño de riñón derecho con presencia de voluminosa tumoración sólida de aproximadamente 139×94×80 $\mathrm{mm}$ localizado a nivel de tercio medio e inferior con extensas áreas de necrosis central, que parecía infiltrar parte de la grasa perirrenal lateral; en hígado múltiples tumoraciones sólidas, la mayoría menores de $5 \mathrm{~mm}$ con necrosis central y que comprometía más del $60 \%$ del parénquima hepático, sugestivas de metástasis; en pulmón presencia de hasta 5 imágenes nodulares menores de $5 \mathrm{~mm}$ en región basal parahiliar derecha sugestivas de metástasis (Figura 1, A y B). Oncología indicó tratamiento con sunitinib 50 mg/día.

Once meses después, durante control en consultorio externo de urología se solicitó estudio tomográfico de control donde se evidenció de forma incidental la glándula tiroides con incremento de su volumen, márgenes lobulados y nódulos parenquimales, algunos calcificados de hasta $9 \mathrm{~mm}$ (Figura 1, C); con este resultado se indicó evaluación por endocrinología, donde se solicitó ecografía de cuello cuyo resultado fue: lóbulo tiroideo derecho de 29×17×10 mm, volumen 2,5 cc, con presencia de nódulo heterogéneo de $13 \times 8 \mathrm{~mm}$ con calcificaciones en su interior localizado en tercio medio, lóbulo tiroideo izquierdo de $32 \times 13 \times 10 \mathrm{~mm}$, volumen $2 \mathrm{cc}$, con pequeños quistes en su interior. Pruebas de laboratorio: TSH: 9,038, T3L: 1,76, T4: 0,94; tiroglobulina 73,30 , anti-tiroglobulina $<15$, antimicrosomales 42,70 . Se indicó tratamiento de hipotiroidismo con levotiroxina $100 \mathrm{mg}$, $1 / 2$ tableta en ayunas lunes, miércoles y viernes. En la evaluación en consultorio externo de cirugía de cabeza y cuello, la paciente negó disfagia, negó disfonía, negó disnea; en el examen físico se palpó nódulo indurado de aproximadamente $1,5 \mathrm{~cm}$ en polo inferior de lóbulo tiroideo izquierdo, poco móvil con la deglución, bordes poco definidos, no se palparon adenopatías cervicales. Se realizó en dos oportunidades biopsias por aspiración con aguja fina medianre guía ecográfica, siendo el resultado: indeterminado.

Teniendo en cuenta los hallazgos al examen físico, las características ecográficas sugestivas de malignidad (nódulo heterogéneo con calcificaciones internas) y el antecedente de carcinoma renal, se indicó realizar tiroidectomía total de manera electiva. Los hallazgos intraoperatorios fueron: lóbulo tiroideo izquierdo de $4 \times 3 \mathrm{~cm}$, con nódulos de consistencia pétrea de aproximadamente $3 \times 3 \mathrm{~cm}$ de bordes irregulares adheridos a músculos pretiroideos sin infiltrarlos, glándula paratiroides superior infiltrada por tumor adherido a tráquea sin infiltrarla, lóbulo tiroideo derecho de $3 \times 3 \mathrm{~cm}$ de consistencia aumentada con presencia de nódulo pétreo de $2 \times 2 \mathrm{~cm}$. El informe anátomo patológico indicó que se observaban dos neoplasias malignas, una primaria y la otra metastásica. La primaria carcinoma papilar de tiroides bien diferenciado, patrones papilar y folicular, la neoplasia presentó un patrón de crecimiento expansivo, bien delimitada, parcialmente encapsulada, con mínima invasión tiroidea y extratiroidea focal, y comprometía lóbulo derecho e istmo; no se observó invasión vascular ni perineural, borde de sección focalmente en contacto con la neoplasia (Figura 2, A). El lóbulo izquierdo presentó metástasis de carcinoma de células claras de riñón, focalmente en contacto con el borde de sección (Figura 2, B y C).

De acuerdo al protocolo de manejo del carcinoma papilar de tiroides, se procedió con la ablación con iodo 131, recibiendo $80 \mathrm{mCi}$; posteriormente, se inició hormonosupresión con levotiroxina. Se indicaron controles trimestrales con TSH, T3, T4L, tiroglobulina y anti-tiroglobulina así como control anual de rastreo corporal con I-131 que hasta la actualidad evidencian adecuado control de la enfermedad neoplásica tiroidea.

En último control tomográfico corporal comparativo anual informó de hasta cuatro pequeños nódulos pulmonares, dos de ellos se observaron en el estudio anterior, y los otros dos no se observaron. Leve derrame pleural laminar basal bilateral y pericárdico que no se observaba en el estudio anterior. Hígado con marcada hepatomegalia y múltiples nódulos sólidos hipercaptadores que comprometían más del 50\% del parénquima hepático, del mismo tamaño y número que en el estudio anterior. La tumoración renal también se mantuvo de igual tamaño en relación al estudio anterior. Oncología mantuvo el tratamiento con sunitinib.

\section{DISCUSIÓN}

El término "tumor de colisión" se refiere a la coexistencia de dos tumores independientes que son histológicamente distintos, separados por tejido normal ${ }^{(11,12)}$. Se han 

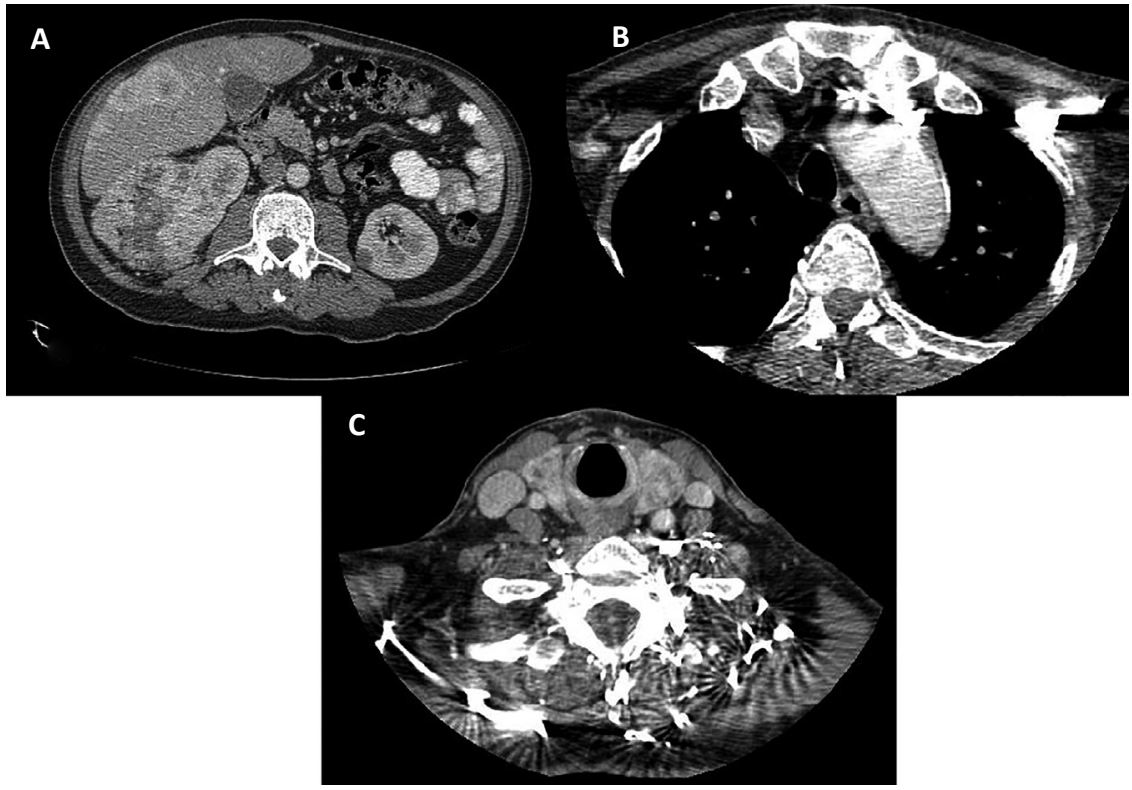

Figura 1. A. TAC abdómino pélvica: nódulos hepáticos metastásicos y tumor renal derecho. B. Corte axial de TAC de tórax: múltiples nódulos pulmonares metastásicos. C. Corte axial de TAC cervical: nódulos en ambos lóbulos tiroideos.

sugerido algunas hipótesis para la formación de un tumor de colisión. La primera y la más simple es que los dos tumores primarios se desarrollaron en el mismo lugar de manera accidental. Una segunda hipótesis es que la presencia del primer tumor alteró el microambiente, como el flujo sanguíneo, presión de oxígeno, y/o diferenciación de las células madres, haciendo más probable el desarrollo del segundo tumor adyacente ${ }^{(13)}$. Esta explicación representa una posible etiología para el paciente de este caso.

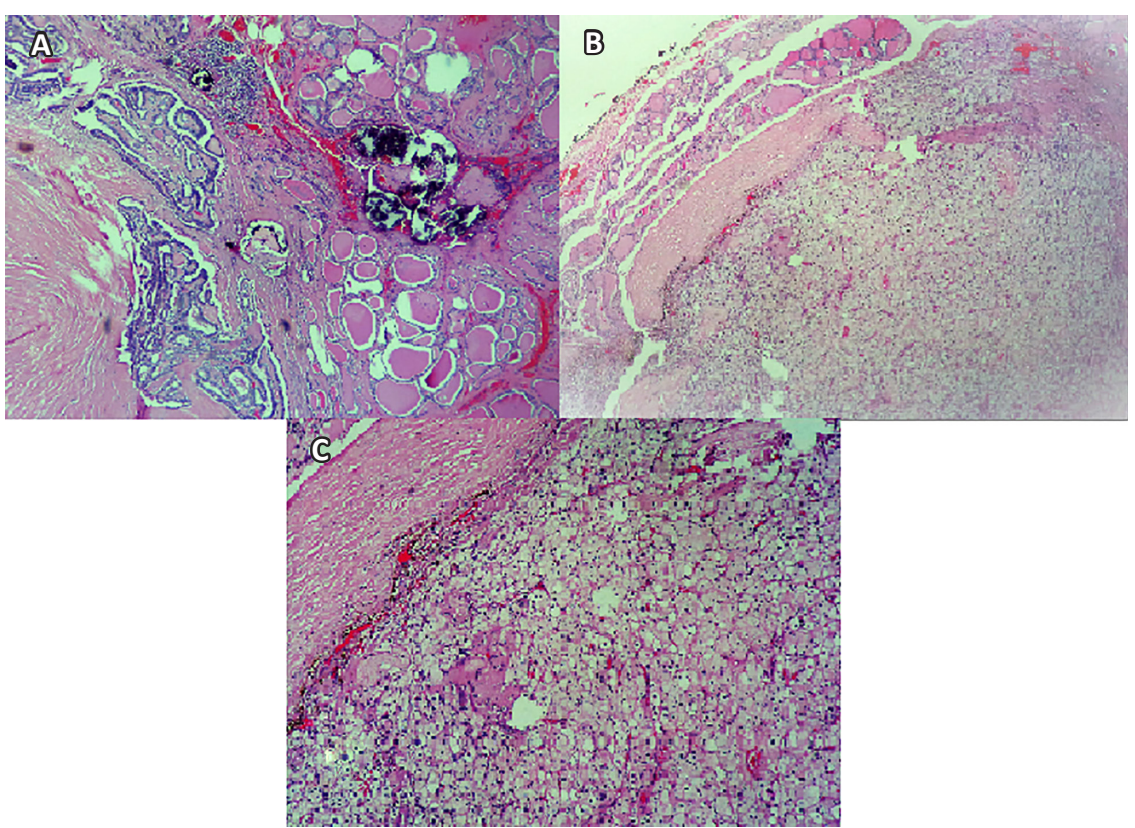

Figura 2. A. Se observa el carcinoma papilar clásico, parcialmente encapsulado, con presencia de cuerpos de psammoma; hematoxilina-eosina, 40x. B. Se observa la metástasis a glándula tiroides del carcinoma renal a células claras, primario renal, bien circunscrita, muy vascularizada, con hemorragia periférica; hematoxilina-eosina, 20x. C. Se observa, a mayor aumento, la metástasis del carcinoma renal a células claras a la glándula tiroides; hematoxilina-eosina, 40x.
El carcinoma papilar de tiroides representa la neoplasia maligna tiroidea más común, mientras que la metástasis a tiroides del carcinoma renal a células claras es una entidad clínica rara y cuya patogénesis no es muy clara ${ }^{(11)}$. La glándula tiroides es uno de los sitios metastásicos inusuales para el carcinoma renal a células claras, y las metástasis pueden ocurrir varios años después del diagnóstico del tumor renal primario ${ }^{(14)}$. La metástasis intratiroidea usualmente representa un evento terminal en la diseminación tumoral y no plantea un problema diagnóstico significativo ${ }^{(15)}$. La probable ruta de metástasis del riñón involucra el plexo venoso paravertebral de Batson, evitando los pulmones ${ }^{(14)}$.

Este caso presenta el carcinoma papilar de tiroides y metástasis a tiroides de carcinoma renal a células claras que ocurren en la misma masa tumoral; cada componente muestra las características típicas para el respectivo tipo tumoral.

El tratamiento de elección en el cáncer papilar de tiroides es la cirugía seguida de ablación con I-131 y hormonosupresión con levotiroxina. En el presente caso se realizó tiroidectomía total; y al tener el informe de anatomía patológica, el paciente recibió el tratamiento correspondiente al carcinoma papilar de tiroides y al carcinoma renal a células claras metastásico a distancia (tiroides).

\section{REFERENCIAS BIBLIOGRÁFICAS}

1. Jacobson A, Wenig B, Urken M. Collision Tumor of the Thyroid and Larynx: A Patient with Papillary Thyroid Carcinoma Colliding with Laryngeal Squamous Cell Carcinoma. Thyroid. 2008;18 (12): 1325-28. DOI: 10.1089/thy.2008.0280

2. Mofiyinfolu S, Carissa T, Marcia E. A Rare Collision Tumor: Tracheal Sarcomatoid Carcinoma Invading a Papillary Thyroid Carcinoma. Open Access Library Journal. 2017; 4: e4012. DOI: 10.4236/ oalib.1104012

3. Plauche V, Dewenter T, Walvekar R. Follicular and Papillary Carcinoma: A Thyroid Collision Tumor. Indian J of Otolaryngol Head Neck Surg. 2013;65(Suppl 1): S182 - 84. DOI: 10.1007/s12070011-0450-0

4. Thomas V, George R. Collision tumors of the thyroid: Review of literature and report of a case of papillary-Follicular collision tumor. Thyroid Res Pract. 2018;15(2):60-4. DOI: 10.4103/trp.trp_6_18

5. Takano K, Kikuchi K, Matsumiya H, Himi T. Collision tumor of the thyroid: follicular carcinoma plus papillary carcinoma plus adenomatous goiter. World $\mathrm{J}$ 
Med Surg Case Rep. 2013;2(5): 21-5.

6. Rossi S, Fugazzola L, De Pasquale L, Braidotti P, Cirello V, Beck-Peccoz P, et al. Medullary and papillary carcinoma of the thyroid gland occurring as a collision tumour: report of three cases with molecular analysis and review of the literature. Endocr Relat Cancer. 2005;12(2): 281 - 89. DOI: 10.1677/erc.1.00901

7. De La Fuente M, Osorio I, Gutiérrez M, Martínez J, De La Cruz F. Metástasis en tiroides de carcinoma renal de células claras. Endocrinol Nutr. 2014;61(5): 296-97.

8. Fernández M, Aguilar C, Fresno M. Metástasis tiroidea de un carcinoma de células renales. Hallazgos citológicos e histológicos. Rev Esp
Patol. 2008;41(3):207-10. DOI: 10.1016/S16998855(08)70123-5

9. Bujons A, Pascual X, Rosales A, Villavicencio $H$. Metástasis tiroidea de un carcinoma renal, a propósito de un caso. Arch Esp Urol. 2006;59(8):811-13.

10. Albarrán J, Pontillo $H$, Tellez R, Fernández A Metástasis tiroidea de un carcinoma de células renales a propósito de un caso. Rev Venez de Oncol. 2012;24(2): 152 - 56.

11. Warman M, Lipschitz N, Ikher S, Halperin D. Collision Tumor of the Thyroid Gland: Primary Squamous Cell and Papillary Thyroid Carcinoma. ISRN Otolaringol. 2011: 582374. DOI: $10.5402 / 2011 / 582374$
12. Walvekar R, Kane S, D'Cruz A. Collision tumor of the thyroid: follicular variant of papillary carcinoma and squamous carcinoma. World J of Surg Oncol. 2006;4: 65. DOI: 10.1186/1477-7819-4-65

13. Brandwein-Gensler M, Urken M, Wang B. Collision tumor of the thyroid: a case report of metastatic liposarcoma plus papillary thyroid carcinoma. Head Neck. 2004;26(7):637-41. DOI: 10.1002/hed.20024

14. Qian L, Pucci R, Castro C, Eltorky M. Renal Cell Carcinoma Metastatic to Hürthle Cell Adenoma of Thyroid. Ann Diagn Pathol. 2004;8(5):305-08. DOI: 10.1016/j.anndiagpath.2004.07.011

15. Ryska A, Cáp J. Tumor-to-Tumor Metastasis of Renal Cell Carcinoma into Oncocytic Carcinoma of the Thyroid. Pathol Res Pract. 2003;199(2):101-06. DOI: 10.1078/0344-0338-00361 